\title{
Review: Trauma-focused psychological treatments improve post- traumatic stress disorder symptoms
}

Bisson JI, Ehlers A, Matthews R, et al. Psychological treatments for chronic post-traumatic stress disorder. Systematic review and meta-analysis. Br J Psychiatry 2007;190:97-104.

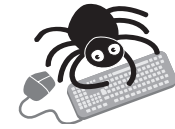

METHODS

\begin{tabular}{|c|c|}
\hline & Design: Systematic review with meta-analysis. \\
\hline 正 & $\begin{array}{l}\text { Data sources: EMBASE, MEDLINE, PsycINFO, CINAHL, and the } \\
\text { Cochrane Library searched in August } 2004 \text {, plus hand searches } \\
\text { of relevant articles and contact with experts for unpublished data } \\
\text { or publications in press. }\end{array}$ \\
\hline & $\begin{array}{l}\text { Study selection and analysis: Randomised controlled trials } \\
\text { (RCTs) of psychological treatments in adults with post-traumatic } \\
\text { stress disorder (PTSD) that met the following criteria: PTSD was } \\
\text { the main target of treatment; participants had PTSD symptoms for } \\
\text { at least three months; at least 70\% had diagnosis of PTSD; PTSD } \\
\text { measured using recognised scale; report at least pre- and post- } \\
\text { treatment measures; and at least 50\% follow-up. Only English } \\
\text { language abstracts were selected. Study appraisal and data } \\
\text { extraction were carried out by a team of researchers. Studies } \\
\text { were assessed against quality criteria, including: random } \\
\text { sequence generation; allocation concealment; blinded } \\
\text { assessment; withdrawals; tolerability; reporting of data; intention- } \\
\text { to-treat analysis. }\end{array}$ \\
\hline 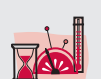 & $\begin{array}{l}\text { Outcomes: Retaining a diagnosis of PTSD; severity of PTSD } \\
\text { symptoms (rated by assessor and by self-report). }\end{array}$ \\
\hline
\end{tabular}

\section{MAIN RESULTS}

The review included 38 RCTs of psychological treatments compared with waiting list/usual care or each other: 25 RCTs were of traumafocused cognitive behavioural therapy (TFCBT); 12 of eye movement desensitisation and reprocessing (EMDR); seven of stress management; six of other psychological treatments (includes supportive therapy, non-directive counselling, psychodynamic therapy, and hypnotherapy); and four of group cognitive behavioural therapy (CBT). TFCBT and EMDR both improved PTSD symptoms and reduced the number of people with PTSD diagnosis compared with waiting list/usual care (see http://ebmh.bmj.com/supplemental for table 1). A small number of RCTs investigating stress management, group CBT or other psychological therapies compared with waiting list/usual care did not consistently find significant differences between the groups. Based on direct comparison studies, the reviewers found that there was unlikely to be a clinically important difference between TFCBT and EMDR (see http://ebmh.bmj.com/ supplemental for table 2). TFCBT and EMDR reduced PTSD symptoms compared with other therapies. Comparison between stress management and other therapies suggests that stress management may be more effective for PTSD symptoms. There is unlikely to be a clinically important difference between group TFCBT and group CBT (not trauma focused). The studies did not present data on adverse events, and results for withdrawals were generally inconclusive.

For correspondence: Dr Jonathan Bisson, Department of Psychological Medicine, Monmouth House, University Hospital of Wales, Health Park, Cardiff CF14 4XN, UK; bissonji@cf.ac.uk

Sources of funding: Not stated.

\section{CONCLUSIONS}

Psychological treatments that focus on trauma (trauma-focused CBT and EMDR) improve PTSD symptoms compared with waiting list/ usual care. There is some indication that trauma-focused CBT and EMDR may be more effective than other types of psychological treatment.

\section{Commentary}

Divition. ost-traumatic stress disorder (PTSD) was first included in the DSMIV ${ }^{1}$ as an official diagnosis in 1980. Since then there has been a strongly growing interest in psychiatric disorders triggered by traumas. The lifetime prevalence of exposure to one or more traumatic events is between $40 \%$ and $90 \%$, and about $15 \%$ to $24 \%$ of these instances develop into PTSD. ${ }^{2} 3$ Bearing in mind that traumatic events can also lead to other kinds of disorder, such as major depression, anxiety disorders, substance-use disorders, etc, then the figures are in fact a great deal higher. This means that we are dealing here with a syndrome that has enormous repercussions on health policy, and accordingly effective treatment is of crucial importance not only for those people affected and their families, but also for (national) health systems.

In the last 20 years numerous comparative therapy studies have been published comparing two or more methods for treating PTSD. Regrettably, these studies have been undertaken more frequently by representatives of individual therapy methods than by independent authors. This being the case, there is a compelling necessity for metaanalyses centring on inclusion and exclusion criteria that have been established on a methodical basis. Earlier meta-analyses have clearly indicated the superiority of EMDR and trauma-focused cognitivebehavioural treatments. It is thus gratifying that with the investigation by Bisson and colleagues we have another study that is not angled towards one particular therapy method and comes up with findings that demonstrate the superiority of these two therapeutic approaches without indicating any significant clinical differences between them. We reached the same outcome in our own meta-analysis. ${ }^{4}$

The practical conclusion to be drawn from this is that it is essential to discontinue the use of non-trauma-adapted therapy approaches (psychoanalysis, unmodified psychodynamic therapy, traditional cognitivebehavioural therapy) and to offer training courses in the methods and techniques of trauma exposure. We need studies testing differential indications for exposure treatment and also investigating which features displayed by patients make it advisable to forgo exposure treatment in favour of stabilising interventions.

Professor Dr Günter H Seidler, Dr Frank E Wagner

University of Heidelberg, Psychotraumatology Section, Hospital for Psychosomatic and General Clinical Medicine, Heidelberg, Germany Competing interests: None.

1 American Psychiatric Association. Diagnostic and Statistical Manual of Mental Disorders, 4th edition - DSM-IV. Washington, DC: American Psychiatric Association, 1994

2 Breslau N. The epidemiology of posttraumatic stress disorder: what is the extent of the problem? J Clin Psychiatry 2001;62(Suppl 17):16-22.

3 Breslau N. Epidemiologic studies of trauma, posttraumatic stress disorder, and other psychiatric disorders. Can J Psychiatry 2002;47:923-9.

4 Seidler GH, Wagner FE. Comparing the efficacy of EMDR and traumafocused cognitive-behavioral therapy in the treatment of PTSD: a metaanalytic study. Psychol Med 2006;36:1515-22. 